\title{
Analisis Pengaruh Tingkat Kompetisi dan Interaksi antara Prey dan Predator pada Perilaku Model Dinamik Diskrit Lotka-Volterra
}

\author{
Ambar Winarni $^{1 *}$, Afifah Hayati $^{2 *}$, Nur'aini Muhassanah $^{3}$ \\ 1,2,3 Universitas Nahdlatul Ulama Purwokerto \\ *a.winarni@unupurwokerto.ac.id
}

\begin{abstract}
ABSTRAK
Salah satu bentuk interaksi makhluk hidup di bumi ini adalah predasi, yang secara matematis dapat disajikan dalam model Lotka-Volterra. Dalam penelitian ini, dikaji model dinamik diskrit LotkaVolterra yang diperoleh dengan menggunakan metode skema beda hingga tak standar. Perilaku dari titik kesetimbangan model bersifat stabil asimtotis lokal jika memenuhi syarat masing-masing titik kesetimbangan. Perubahan nilai parameter akan memberikan pengaruh pada perubahan kestabilan titik kesetimbangan. Analisis sensitivitas terhadap koeksistensi titik kesetimbangan dilakukan secara numerik. Kenaikan tingkat kompetisi antar predator dan tingkat interaksi predator terhadap prey mengakibatkan kenaikan jumlah populasi predator.
\end{abstract}

Kata kunci: model lotka-volterra, metode skema beda hingga tak standar, titik kesetimbangan, analisa kestabilan.

\begin{abstract}
One of interpopulation interaction of organisms is predation which is mathematically can be expressed in Lotka-Volterra model. In this research, are reviewed dynamic discrete Lotka-Volterra model that can be obtained by nonstandard finite difference schemes method. The behavior of equilibrium point of model is local asymptotically stable if qualified each point equilibrium. The change of parameters values will give impact on change stability of equilibrium point. Sensitivity analysis for the stability of the coexistence equilibrium is done numerically. The increase in the rate of competition between predator and the rate of interaction predator to prey resulted in an increase the number of predator.

Keywords: lotka-volterra model, nonstandard finite difference schemes method, fixed point, stability analysis.
\end{abstract}




\section{PENDAHULUAN}

Makhluk hidup di bumi ini sangat beraneka ragam, terdiri dari berbagai spesies yang hidup bersama dan membentuk populasi. Hal ini menunjukkan bahwa pada hakikatnya makhluk hidup di bumi ini tidak dapat hidup sendiri secara normal, tetapi akan saling berinteraksi dengan berbagai spesies lain. Interaksi yang terjadi dapat berupa predasi (makan dimakan) (Kurniawan, 2011).

Predasi merupakan hubungan antara mangsa (prey) dan pemangsa (predator). Hubungan antara pemangsa dan mangsa dapat dimodelkan secara matematika sehingga dapat diselesaikan secara matematis. Model matematika yang menggambarkan hubungan tersebut disebut model predator-prey. Model predator-prey yang paling sederhana diperkenalkan oleh A.J. Lotka pada tahun 1925 dan V. Volterra pada tahun 1926. Model tersebut dikenal dengan istilah Model Lotka-Volterra.

Model Lotka-Volterra yang sering muncul biasanya menggunakan sistem dinamik kontinu, dimana perubahan populasinya terjadi setiap saat dan biasanya menggunakan persamaan diferensial. Namun, dalam kehidupan nyata, perubahan tersebut tidak setiap saat dapat diketahui atau dengan kata lain hanya dapat diketahui pada waktu-waktu tertentu saja. Hampir apa pun yang berkembang dari waktu ke waktu dapat dianggap sebagai sistem dinamik dan perubahan yang terjadi selanjutnya dapat diketahui (Scheinerman,2000). Perubahan populasi spesies pada waktu berikutnya akan dipengaruhi oleh populasi pada waktu sebelumnya (Grossman dan Turner, 1974). Kasus seperti ini lebih tepat digambarkan dengan menggunakan sistem diskrit, sehingga dimodelkan dengan menggunakan persamaan beda.

Model diskrit dapat diperoleh dengan cara mentransformasikan model kontinu menjadi model diskrit. Proses tersebut dikenal dengan istilah diskritisasi. Din (2013) telah mengkaji model dinamik diskrit Lotka-Volterra dan menganalisis perilaku kedua populasi secara lokal dan global. Penulis tertarik untuk mengkaji kembali perilaku dari kestabilan sistem secara lokal dan melakukan analisa sensitivitas perilaku model dengan mengacu model dinamik diskrit Lotka-Volterra Din (2013) tersebut. Penelitian ini dibatasi hanya mendeskripsikan model dinamik diskrit Lotka-Volterra (Din,2013), mengkaji perilaku dari kestabilan sistem secara lokal dan melakukan analisa sensitivitas nilai parameter terhadap jumlah populasi prey dan predator disertai simulasi numerik.

\section{METODE}

Metode yang digunakan dalam penelitian ini adalah metode penelitian kepustakaan, yaitu dengan mengumpulkan data dan informasi dari berbagai sumber seperti buku dan jurnal. Penelitian ini dilakukan dengan mengkaji teorema-teorema sistem dinamik diskrit dari literatur yang diperoleh, kemudian diterapkan pada masalah-masalah pada kehidupan nyata, salah satunya yaitu predasi. Langkah-langkah yang dilakukan dalam penelitian ini adalah sebagai berikut. 1) Mendeskripsikan model dinamik diskrit Lotka-Volterra (Din,2013), 2) mencari penyelesaian model dengan menentukan titik kesetimbangan model dan menganalisis perilaku di setiap titik kesetimbangan model, dan 3) analisa sensitivitas dan simulasi numerik model diskrit Lotka-Volterra. 


\section{HASIL DAN PEMBAHASAN}

\subsection{Deskripsi Model}

Dalam kajiannya, Din (2013) menggunakan model Lotka-Volterra yang dimodifikasi, yaitu dengan menggunakan model pertumbuhan logistik pada pertumbuhan populasi predator dan prey. Model Lotka-Volterra merupakan model yang menggambarkan interaksi predator dan prey atau interaksi kompetitif antara dua spesies (Soetaert dan Herman, 2009). Hal ini terjadi karena populasi tersebut dianggap mengalami interaksi kompetisi antarspesies. Model tersebut mempunyai beberapa asumsi, yaitu:

a. populasi predator dan populasi prey bersifat tertutup, dengan kata lain tidak ada predator maupun prey yang melakukan migrasi,

b. model yang dikaji terdiri dari satu predator dan satu prey,

c. terjadi interaksi kompetisi antara predator yang satu dengan yang lainnya yang digambarkan oleh model pertumbuhan logistik, begitu juga dengan prey, dimana kompetisi ini menggunakan pendekatan non lokal.

Berikut adalah model dinamik kontinu yang dikaji oleh Din (2013).

$$
\begin{aligned}
& \frac{d x}{d t}=a x-b x^{2}-c x y \\
& \frac{d y}{d t}=p y-q y^{2}+r x y .
\end{aligned}
$$

Keterangan:

$x(t)$ : jumlah prey pada saat $t$

$y(t)$ : jumlah predator pada saat $t$

$t \quad$ : waktu

$a$ : tingkat pertumbuhan prey

$p$ : tingkat pertumbuhan predator

$b$ : tingkat kompetisi antar prey

$q$ : tingkat kompetisi antar predator

$c$ : tingkat interaksi prey terhadap predator

$r \quad$ : tingkat interaksi predator terhadap prey

Model tersebut merupakan gabungan dari model pertumbuhan logistik dan model predatorprey yang dikonstruksi oleh Edwards dan Penney (2007) . Selanjutnya dilakukan diskritisasi model untuk memperoleh model dinamik diskrit dari sistem (1).

Diskritisasi merupakan proses mentransformasikan model kontinu menjadi model diskrit. Diskritisasi dilakukan dengan membawa domain persamaan diferensial ke dalam domain komputasi yang berupa grid atau bagian-bagian kecil (Hoffman, 2001). Dasar pemikiran metode beda hingga adalah Deret Taylor, sehingga diperoleh bentuk beda hingga yang digunakan untuk mendiskritisasi model kontinu sebagai berikut.

$$
\left.x^{\prime}\right|_{n}=\frac{x_{n+1}-x_{n}}{\Delta t}
$$


Model yang akan didiskritisasi adalah model kontinu pada sistem (1). Proses ini menggunakan metode skema beda hingga tak standar, dimana metode ini didasarkan pada sebuah prinsip yaitu penggantian dari fungsi non linier dengan pendekatan non lokal (Mickens, 2005).

$$
x^{2}=x_{k+1} x_{k}
$$

Berdasarkan persamaan (2) dan (3) dan $\Delta t=h$ maka sistem (1) dapat dituliskan dalam bentuk sebagai berikut.

$$
\begin{aligned}
& \left.x^{\prime}\right|_{n}=\frac{x_{n+1}-x_{n}}{h}=a x_{n}-b x_{n}^{2}-c x_{n} y_{n} . \\
& \left.y^{\prime}\right|_{n}=\frac{y_{n+1}-y_{n}}{h}=p y_{n}-q y_{n}^{2}+r y_{n} x_{n} .
\end{aligned}
$$

Dengan menggunakan operasi aljabar dan memisalkan $\delta=1+h p, \eta=h q, \varepsilon=h q, \alpha=1+h a$, $\gamma=h b$, dan $\beta=h c$ maka dari sistem (4) dapat diperoleh model dinamik diskrit Lotka-Volterra berupa sistem persamaan beda non linier yang dapat dilihat pada persamaan berikut ini (Din, 2013).

$$
\begin{aligned}
& x_{n+1}=\frac{\alpha x_{n}-\beta x_{n} y_{n}}{1+\gamma x_{n}} \\
& y_{n+1}=\frac{\delta y_{n}+\varepsilon y_{n} x_{n}}{1+\eta y_{n}} .
\end{aligned}
$$

dengan $\alpha, \delta>-1$ dan $\beta, \gamma, \varepsilon, \eta>0$.

\subsection{Analisis Kestabilan Titik Kesetimbangan}

Model diskrit pada sistem (5) dapat diselesaikan secara kualitatif dengan cara melihat perilaku sistem di sekitar titik kesetimbangan. Misalkan $x_{n+1}=f\left(x_{n}, y_{n}\right), y_{n+1}=g\left(x_{n}, y_{n}\right)$ dan $\left(x^{*}, y^{*}\right)$ merupakan titik kesetimbangan dari sistem (5). Titik kesetimbangan model pada sistem (5) diperoleh jika $f\left(x^{*}, y^{*}\right)=x^{*}$ dan $g\left(x^{*}, y^{*}\right)=y^{*}$ (Luenberger,1979). Dengan demikian diperoleh empat titik kesetimbangan untuk sistem (5), yaitu $T E_{1}=(0,0), T E_{2}=\left(\frac{\alpha-1}{\gamma}, 0\right)$, $T E_{3}=\left(0, \frac{\delta-1}{\eta}\right)$ dan $T E_{4}=\left(\frac{\alpha \eta-\eta-\beta \delta+\beta}{\eta \gamma+\varepsilon \beta}, \frac{\delta \gamma-\gamma+\alpha \varepsilon-\varepsilon}{\eta \gamma+\varepsilon \beta}\right)$.

Model Lotka-Volterra pada sistem (5) merupakan sistem non linear. Analisa perilaku sistem tersebut dilakukan dengan menggunakan matriks Jacobi hasil linierisasi sistem di titik kesetimbangan (Luenberger,1979). Dengan memisalkan $x_{n+1}=f\left(x_{n}, y_{n}\right), y_{n+1}=g\left(x_{n}, y_{n}\right)$ dan $\left(x^{*}, y^{*}\right)$ merupakan titik kesetimbangan dari sistem (5), maka bentuk umum matriks Jacobi hasil linierisasi sistem di titik kesetimbangan $\mathrm{T}$ adalah sebagai berikut. 


$$
J_{(T)}=\left[\begin{array}{ll}
\frac{\partial f\left(x^{*}, y^{*}\right)}{\partial x^{*}} & \frac{\partial f\left(x^{*}, y^{*}\right)}{\partial y^{*}} \\
\frac{\partial g\left(x^{*}, y^{*}\right)}{\partial x^{*}} & \frac{\partial g\left(x^{*}, y^{*}\right)}{\partial y^{*}}
\end{array}\right] .
$$

Elemen-elemen pada matriks Jacobi di titik kesetimbangan $\mathrm{T}$ diperoleh dengan cara menurunkan persamaan-persamaan di dalam sistem (5), sehingga diperoleh bentuk matriks Jacobi sebagai berikut:

$$
J_{(T)}=\left[\begin{array}{cc}
\frac{\alpha-\beta y^{*}}{\left(1+\gamma x^{*}\right)^{2}} & \frac{-\beta x^{*}}{1+\gamma x^{*}} \\
\frac{\varepsilon y^{*}}{1+\eta y^{*}} & \frac{\delta+\varepsilon x^{*}}{\left(1+\eta y^{*}\right)^{2}}
\end{array}\right] .
$$

Dengan membentuk persamaan karakteristik dari Matriks Jacobi diatas $\operatorname{det}\left(\lambda I-J_{(T)}\right)$ diperoleh nilai eigen $\lambda$. Suatu titik kesetimbangan dikatakan stabil asimtotik lokal apabila $|\lambda|<1$, dikatakan stabil apabila $|\lambda|=1$ dan dikatakan tidak stabil apabila $|\lambda|>1$. Jika titik kesetimbangan stabil, maka penyelesaian berada di sekitar titik kesetimbangan. Jika titik kesetimbangan stabil asimtotis, maka penyelesaian akan menuju ke titik kesetimbangan. Jika titik kesetimbangan tidak stabil, maka penyelesaian akan menjauh dari titik kesetimbangan (Luenberger,1979).

Berdasarkan linierisasi disekitar titik kesetimbangan dan nilai eigen yang diperoleh, titik kesetimbangan dari sistem (5) akan stabil asimtotis apabila memenuhi syarat tertentu yaitu :

a. Titik kesetimbangan $T E_{1}$ akan stabil asimtotis jika memenuhi syarat $-1<\alpha<1$ dan $-1<\delta<1$, artinya seiring berjalannya waktu akan terjadi kepunahan populasi predator dan prey.

b. Titik kesetimbangan $T E_{2}$ akan stabil asimtotis jika memenuhi syarat $\alpha>1, \delta<1$ dan $\varepsilon<\frac{\gamma(1-\delta)}{(\alpha-1)}$, artinya seiring berjalannya waktu jumlah prey akan menuju suatu nilai yaitu $\frac{\alpha-1}{\gamma}$ dan terjadi kepunahan pada populasi predator.

c. Titik kesetimbangan $T E_{3}$ akan stabil asimtotis jika memenuhi $\delta>1, \alpha>1$, dan $\frac{\eta(1-\alpha)}{(1-\delta)}<\beta<\frac{\eta(-\alpha-1)}{(1-\delta)}$ atau $\delta>1, \quad \alpha \leq 1$ dan $\beta<\frac{\eta(-\alpha-1)}{(1-\delta)}$, artinya seiring berjalannya waktu jumlah predator akan menuju suatu nilai yaitu $\frac{\delta-1}{\eta}$ dan terjadi kepunahan pada populasi prey. 
d. Titik kesetimbangan $T E_{4}$ akan stabil asimtotis jika memenuhi $\alpha>1, \delta>1, \eta>\frac{\beta(\delta-1)}{(\alpha-1)}$

$$
\begin{aligned}
& \text { atau } \quad \alpha>1, \quad \delta<1, \quad \varepsilon>\frac{\gamma(1-\delta)}{(\alpha-1)} \quad \text { dan } \quad \varphi<(\varepsilon \beta+\eta \gamma+\gamma(\beta(1-\delta)+\eta(\alpha-1)))^{2} \\
& \begin{aligned}
&(\varepsilon \beta+\eta \gamma+\eta(\gamma \delta-\gamma+\alpha \varepsilon-\varepsilon))^{2}, \text { dengan } \\
& \varphi=(\varepsilon \beta+\eta \gamma)(\alpha(\varepsilon \beta+\eta \gamma)+\beta(\gamma \delta+\gamma+\alpha \varepsilon+\varepsilon))(\varepsilon \beta+\eta \gamma+\eta(\gamma \delta+\gamma+\alpha \varepsilon+\varepsilon))^{2} \\
&+(\delta(\varepsilon \beta+\eta \gamma)+\varepsilon(\beta(1+\delta)+\eta(\alpha+1)))(\varepsilon \beta+\eta \gamma)(\varepsilon \beta+\eta \gamma+\gamma(\beta(1+\delta)+\eta(\alpha+1)))^{2} \\
&+\beta(\beta(1+\delta)+\eta(\alpha+1))(\varepsilon(\gamma \delta+\gamma+\alpha \varepsilon+\varepsilon))(\varepsilon \beta+\eta \gamma+\gamma(\beta(1+\delta)+\eta(\alpha+1))) \\
&(\varepsilon \beta+\eta \gamma+\eta(\gamma \delta+\gamma+\alpha \varepsilon+\varepsilon))+(\varepsilon \beta+\eta \gamma)(\alpha(\varepsilon \beta+\eta \gamma)+\beta(\gamma \delta+\gamma+\alpha \varepsilon+\varepsilon)) \\
&(\delta(\varepsilon \beta+\eta \gamma)+\varepsilon(\beta(1+\delta)+\eta(\alpha+1)))(\varepsilon \beta+\eta \gamma) .
\end{aligned}
\end{aligned}
$$

artinya seiring berjalannya waktu jumlah prey akan menuju suatu nilai yaitu $\frac{\alpha \eta-\eta-\beta \delta+\beta}{\eta \gamma+\varepsilon \beta}$ dan jumlah predator akan menuju suatu nilai yaitu $\frac{\delta \gamma-\gamma+\alpha \varepsilon-\varepsilon}{\eta \gamma+\varepsilon \beta}$.

\subsection{Analisis Sensitivitas dan Simulasi Numerik}

Simulasi numerik dilakukan untuk mengetahui perilaku model dalam jangka waktu yang lama dari sistem (5). Simulasi ini menggunakan Software Maple 9.5. Nilai parameter yang digunakan dalam simulasi model yaitu $a=0,5 ; p=0,2 ; b=0,15 ; q=0,08 ; c=0,04$ dan $r=0,14$. Dengan mengambil nilai $\Delta t=h=1$, maka didapatkan nilai $\alpha=1,5 ; \delta=1,2$; $\gamma=0,15 ; \quad \eta=0,08 ; \quad \beta=0,04$ dan $\varepsilon=0,14$. Apabila nilai-nilai parameter tersebut disubtitusikan ke dalam sistem (5), maka diperoleh

$$
\begin{aligned}
& x_{n+1}=\frac{1,5 x_{n}-0,04 x_{n} y_{n}}{1+0,15 x_{n}} \\
& y_{n+1}=\frac{1,2 y_{n}+0,14 y_{n} x_{n}}{1+0,08 y_{n}} .
\end{aligned}
$$

Dari sistem (7) dapat diperoleh titik kesetimbangan, nilai eigen, dan kestabilan titik kesetimbangan seperti pada Tabel 1. Berdasarkan analisa kestabilan, diperoleh hasil bahwa titik kesetimbangan $T E_{4}=(1,82 ; 5,68)$ bersifat stabil asimtotis. Hal ini berarti, pada kasus nilai parameter yang telah diambil bahwa untuk jangka waktu yang lama jumlah prey akan menuju $1,82 \approx 2$ ekor dan jumlah predator akan menuju $5,68 \approx 6$ ekor. Hal tersebut dapat digambarkan dalam Gambar 1 dengan perintah Software Maple 9.5 dan diberikan syarat awal pada sistem (7), yaitu $x(0)=7$ dan $y(0)=6$. 
Tabel 1. Titik Kesetimbangan, Nilai Eigen, dan Kestabilan Titik Kesetimbangan Sistem (5)

\begin{tabular}{ccc}
\hline $\begin{array}{c}\text { Titik } \\
\text { Kesetimbangan } \\
\left(\boldsymbol{x}^{*}, \boldsymbol{y}^{*}\right)\end{array}$ & $\begin{array}{c}\text { Nilai Eigen } \\
\lambda_{1,2}\end{array}$ & $\begin{array}{c}\text { Kestabilan } \\
\text { Titik } \\
\text { Kesetimbangan }\end{array}$ \\
\hline$T E_{1}=(0 ; 0)$ & $(1,5 ; 1,2)$ & Tidak Stabil \\
$T E_{2}=(3,33 ; 0)$ & $(1,667 ; 0,667)$ & Tidak Stabil \\
$T E_{3}=(0 ; 2,5)$ & $(1,4 ; 0,833)$ & Tidak Stabil \\
$T E_{4}=(1,82 ; 5,68)$ & $(0,737 \pm 0,169 I)$ & Stabil Asimtotis
\end{tabular}

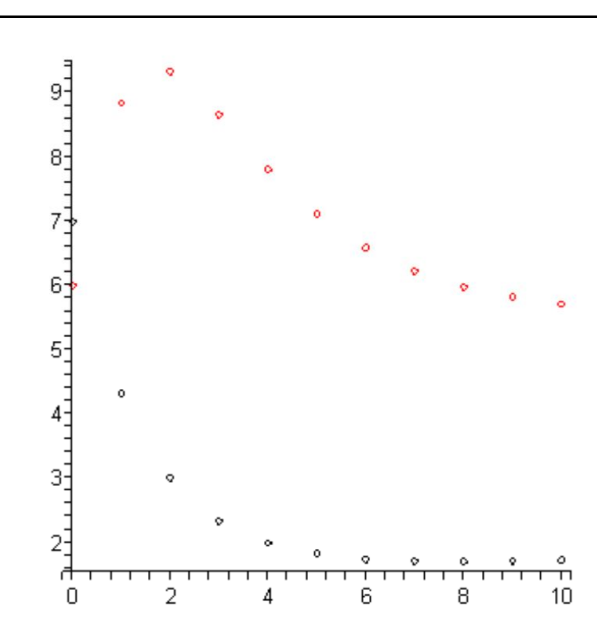

(a) Perilaku prey dan predator untuk waktu singkat

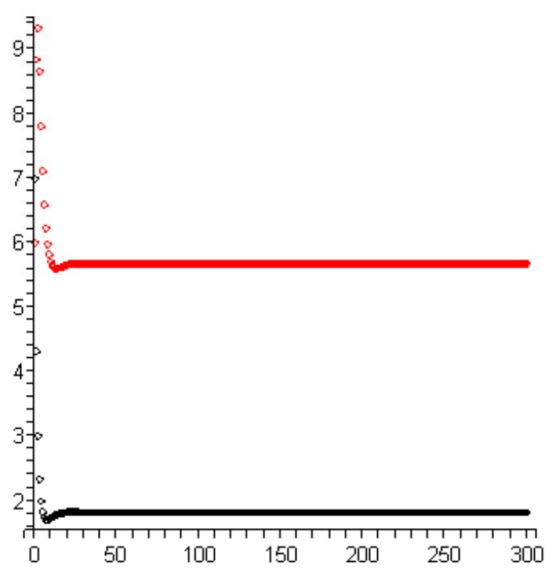

(b) Perilaku prey dan predator untuk jangka waktu lama

Gambar 1. Perilaku Prey dan Predator pada Sistem (5)

Selanjutnya dilakukan analisa sensitivitas dilakukan untuk mengetahui pengaruh perubahan nilai parameter $\gamma, \eta, \beta$ dan $\varepsilon$ terhadap koeksistensi titik kesetimbangan $T E_{4}=\left(x^{*}, y^{*}\right)=\left(\frac{\alpha \eta-\eta-\beta \delta+\beta}{\eta \gamma+\varepsilon \beta}, \frac{\delta \gamma-\gamma+\alpha \varepsilon-\varepsilon}{\eta \gamma+\varepsilon \beta}\right)$. Hal ini dilakukan untuk melihat pengaruh perubahan tingkat kompetisi antar prey, tingkat kompetisi antar predator, tingkat interaksi prey terhadap predator dan tingkat interaksi predator terhadap prey terhadap jumlah populasi prey dan predator. Hal ini dapat dilihat pada Gambar 2 dan Gambar 3.

Berdasarkan Gambar 2 dan Gambar 3, dapat dilihat bahwa perubahan nilai parameter $\gamma$ , $\eta, \beta$ dan $\varepsilon$ mempengaruhi jumlah populasi prey dan predator pada koeksistensi titik kesetimbangan $T E_{4}$. Sebagai contoh, jika tingkat kompetisi antar predator tetap dan tingkat interaksi predator terhadap prey semakin tinggi maka jumlah populasi prey akan menurun dan jumlah populasi predator akan meningkat. Sedangkan jika tingkat interaksi predator terhadap prey tetap dan tingkat kompetisi antar predator semakin tinggi maka jumlah populasi prey akan meningkat dan jumlah populasi predator akan menurun. 


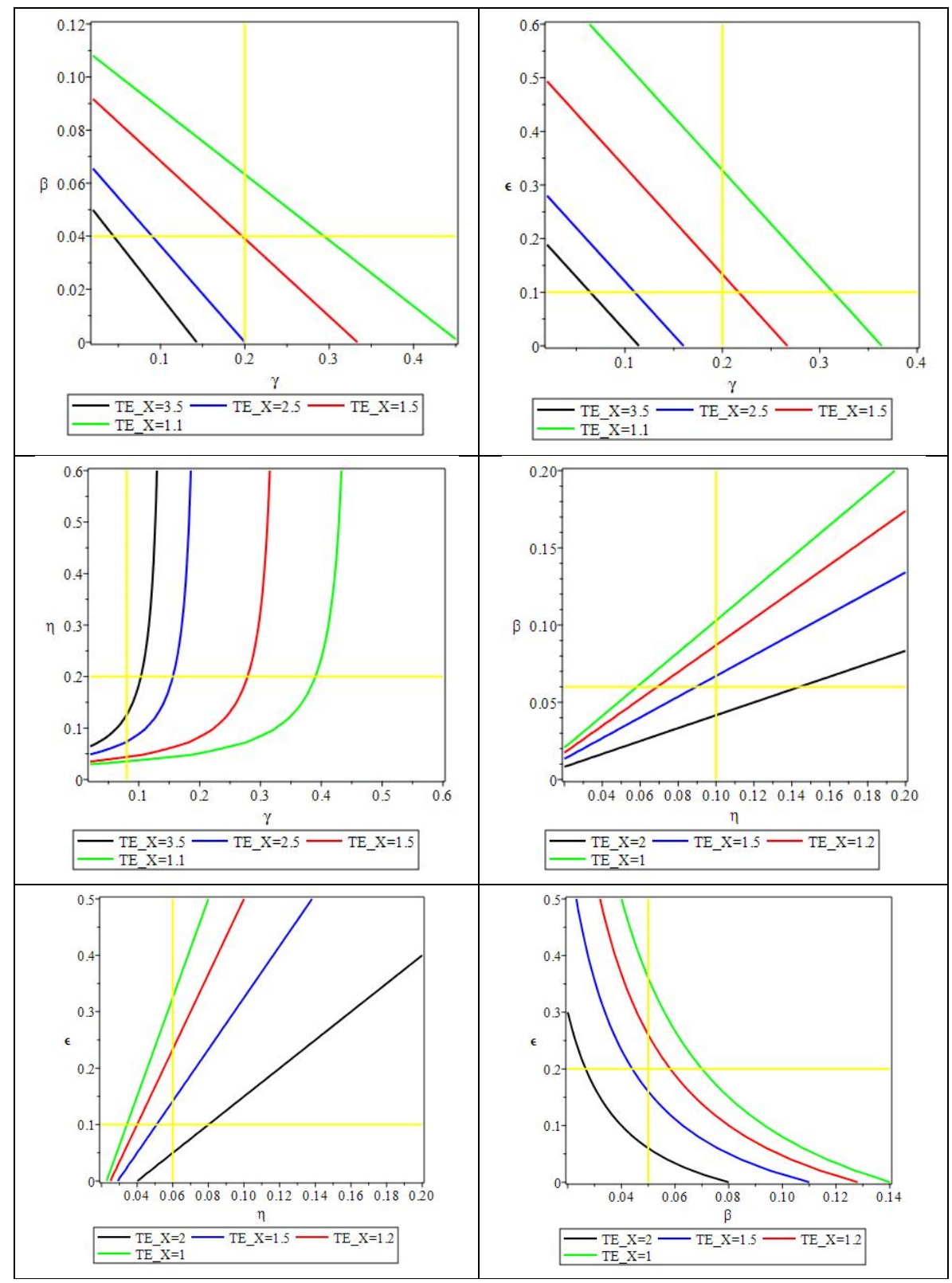

Gambar 2. Analisis Sensitivitas: Perubahan Jumlah Populasi Prey $\left(x^{*}\right)$ pada Titik Kesetimbangan $T E_{4}$ berdasarkan Perubahan Nilai Parameter $\gamma, \eta, \beta$ dan $\varepsilon$ 


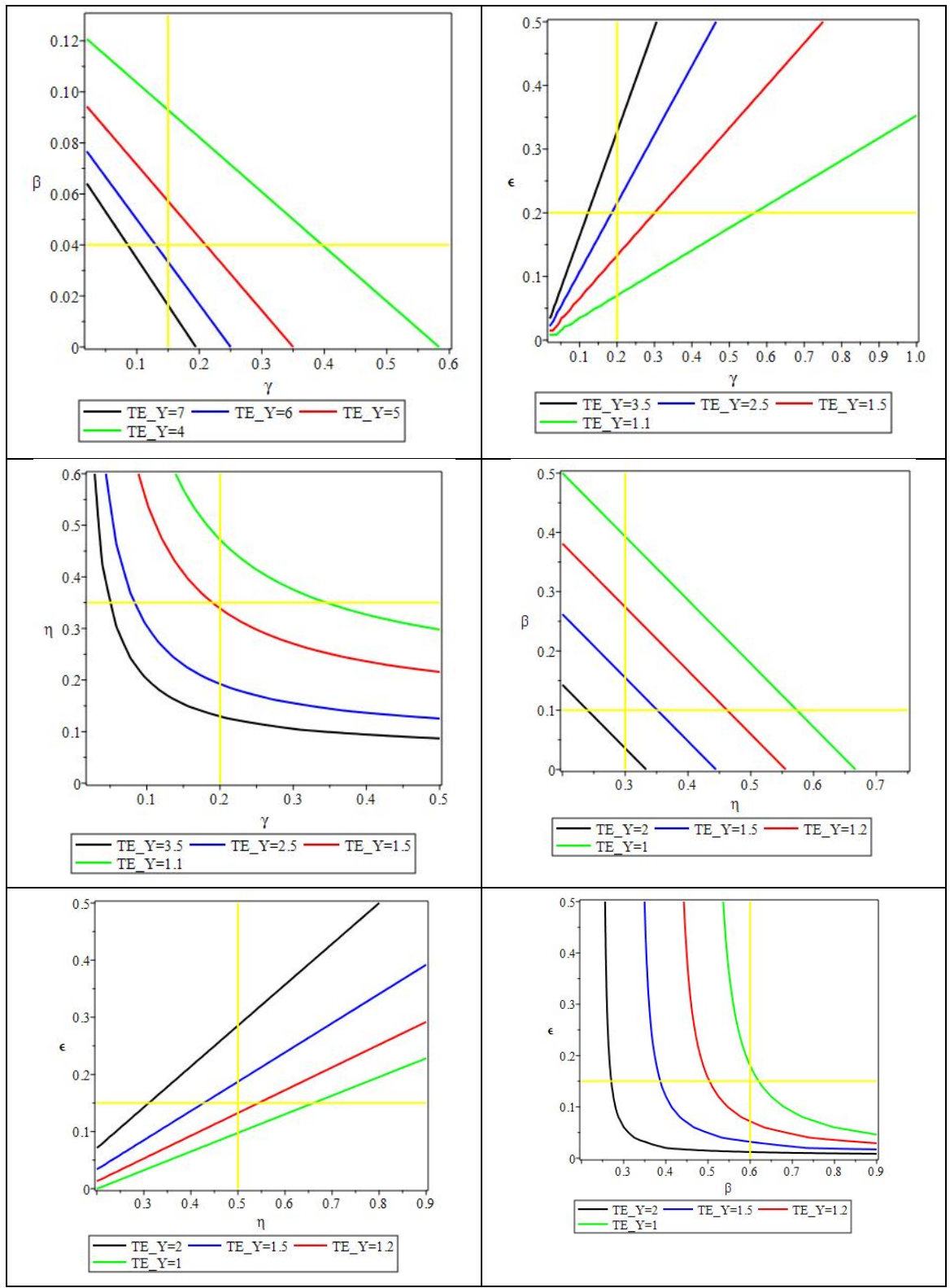

Gambar 3. Analisis Sensitivitas : Perubahan Jumlah Populasi Predator $\left(y^{*}\right)$ pada Titik Kesetimbangan $T E_{4}$ berdasarkan Perubahan Nilai Parameter $\gamma, \eta, \beta$ dan $\varepsilon$

Perubahan jumlah populasi prey dan predator pada koeksistensi titik kesetimbangan $T E_{4}$ dapat dilihat lebih jelas pada Tabel 2. Berdasarkan Tabel 2, dapat disumpulkan bahwa perubahan nilai parameter $\gamma, \eta, \beta$ dan $\varepsilon$ mengakibatkan penurunan jumlah populsi prey dan predator. Namun ketika terjadi kenaikan nilai parameter $\eta$ (tingkat kompetisi antar predator) dan $\varepsilon$ (tingkat interaksi predator terhadap prey) mengakibatkan kenaikan jumlah populasi predator. 
Tabel 2. Perubahan Jumlah Populasi Prey dan Predator pada Koeksistensi Titik Kesetimbangan $T E_{4}$

\begin{tabular}{ccccccccccc}
\multicolumn{10}{c}{ Berdasarkan Perubahan Nilai Parameter $\gamma, \eta, \beta$ dan $\varepsilon$} \\
\hline$\gamma$ & \multicolumn{1}{c}{$\gamma$} & \multicolumn{1}{c}{$\eta$} & & $\beta$ & & \\
Naik & $x^{*}$ & $y^{*}$ & $x^{*}$ & $y^{*}$ & $x^{*}$ & $y^{*}$ & $x^{*}$ & $y^{*}$ \\
$\eta$ & - & - & naik & turun & turun & turun & turun & naik \\
$\beta$ & turun & turun & - & - & turun & turun & turun & naik \\
$\varepsilon$ & turun & turun & naik & turun & - & - & turun & turun \\
\hline & turun & turun & naik & turun & turun & turun & - & - \\
\hline
\end{tabular}

\section{SIMPULAN}

Model dinamik diskrit Lotka-Volterra dengan kompetisi mempunyai empat titik kesetimbangan dan berdasarkan analisis perilaku model, keempat titik kesetimbangan tersebut dapat bersifat stabil asimtotis jika memenuhi syarat tertentu masing-masing titik kesetimbangan. Selanjutnya, analisis sensitivitas dan simulasi numerik memperlihatkan bahwa perubahan nilai parameter akan memberikan pengaruh terhadap jumlah populasi prey dan predator pada koeksistensi titik kesetimbangan $T E_{4}$. Kenaikan nilai parameter $\eta$ (tingkat kompetisi antar predator) dan $\varepsilon$ (tingkat interaksi predator terhadap prey) mengakibatkan kenaikan jumlah populasi predator.

\section{DAFTAR PUSTAKA}

Din, Q. (2013). Dynamic of a Discrete Lotka-Volterra. Advances in Difference Equations: Springer Open.

Edwards, C. H. dan Penney, D. E. (2007). Differential Equations and Boundary Value Problems. New Jersey: Prentice-Hall.

Grossman, S. I. dan Turner, J. E. (1974). Mathematics for the Biological Sciences. New York: Macmillan.

Hoffman, D. J. (2001). Numerical Methods for Engineers and Scientists. Second Edition. New York: Marcel Dekker, Inc.

Kurniawan, W. (2011). Interaksi Makhluk Hidup antar Spesies. Di unduh dari : http://blog.uad.ac.id/wahyukurniawan (Diakses pada 22 Desember 2018).

Luenberger, D. G. (1979). Introductions to Cynamics System: Theory, Models \& Applications. New York: John Wiley \& Son.

Mickens, R. E. (2005). Advances in the Applications of Nonstandard Finite Difference Schemes. USA: World Scientific.

Scheinerman, E. R. (2000). Dynamical Systems. USA: Department of Mathematical Sciences The Johns Hopkins University.

Soetaert, K dan Herman, P. M. J. (2009). A Practical Guide to Ecological Modelling. Netherlands: Spinger. 